\title{
Avaliação externa da gestão escolar do Programa Nova Escola do Estado do Rio de Janeiro: um estudo reflexivo sobre o seu primeiro ciclo de realização (2000-2003), passados quinze anos de sua implementação
}

Ovidio Orlando Filho a Virgínio Isidro Martins Sá ${ }^{b}$

\section{Resumo}

Este artigo objetiva analisar reflexivamente os impactos ocasionados pela avaliação externa da gestão escolar, do Programa Nova Escola, implementada na rede pública de ensino básico do Estado do Rio de Janeiro. Para consecução da investigação realizada, foi dada voz aos atores participantes do contexto investigado, avaliados e avaliadores, de forma a identificar as possíveis mudanças no modo de pensar e praticar a gestão nas escolas componentes da rede considerada, induzidas pela avaliação externa do eixo gestão escolar em seu primeiro ciclo de realização (2000-2003). O tema abordado é apresentado por meio de uma breve descrição do processo avaliativo realizado; de uma exposição concisa da estrutura organizacional montada para a implementação da avaliação; da explicitação da metodologia utilizada para a consecução da pesquisa; e por uma apresentação dos principais resultados da pesquisa realizada.

Palavras-chave: Avaliação. Gestão escolar. Nova Escola.

\section{Introdução}

O Governo do Estado do Rio de Janeiro instituiu, a partir do último ano do século $\mathrm{XX}$, a implantação de um programa no campo educacional que teve como um dos

\footnotetext{
a Fundação Cesgranrio, Mestrado Profissional em Avaliação. Rio de Janeiro, Rio de Janeiro, Brasil.

b Universidade do Minho, Instituto de Educação e Psicologia, Departamento de Sociologia da Educação e Administração Educacional. Braga, Portugal.
} 
principais objetivos estabelecer um projeto de avaliação externa das unidades de ensino básico público de sua órbita de responsabilidade. A avaliação realizada foi instituída em um momento em que os sistemas de avaliação da educação tiveram uma grande expansão no Brasil, tendo um grande estímulo do governo central do país, logo seguido por um grande número de estados da Federação que, então, passaram a se preocupar em realizar avaliações direcionadas, também, ao aperfeiçoamento dos instrumentos e metodologias da gestão educacional.

O processo avaliativo foi criado pelo Decreto $\mathrm{n}^{\mathrm{o}} 25.959$, de 12 de janeiro de 2000 (RIO DE JANEIRO, 2000), por meio do qual o Governo do Estado do Rio de Janeiro criou o Programa Estadual de Reestruturação da Educação Pública - Programa Nova Escola (PrNE), que estabeleceu a avaliação externa como parte de sua estratégia de procurar garantir melhores padrões de qualidade para suas escolas de ensino básico público. O Decreto estabeleceu em seu escopo os critérios de avaliação das escolas em cinco itens: prestação de contas, gestão da matrícula, integração com a comunidade, desempenho dos alunos e fluxo escolar.

A avaliação externa do PrNE teve duas edições, ou ciclos, a primeira realizada pela Fundação Cesgranrio, instituição especializada em pesquisa e avaliação educacional, com sede na cidade do Rio de Janeiro/RJ, no período de 2000 a 2003. Nesse primeiro período, observa-se que a rede estadual foi avaliada nos anos de 2000, 2001 e 2003, sendo interrompida, por questões políticas, no ano $2002^{1}$. Em sequência, a segunda edição, a partir de 2004 até 2008, foi realizada pelo Centro de Políticas Públicas e Avaliação da Educação da Universidade Federal de Juiz de Fora. A partir de 2008, foi criado um novo programa avaliativo para seu sistema de educação básica, o Sistema de Avaliação do Estado do Rio de Janeiro (SAERJ), cujo objetivo é o de promover uma análise do desempenho dos alunos de rede pública do Estado nas áreas de Língua Portuguesa e Matemática do $4^{\mathrm{o}}$ ano do Ensino Fundamental e da $3^{\mathrm{a}}$ série do Ensino Médio.

Uma característica peculiar e bastante discutida do PrNE era o fato de conceder gratificações aos profissionais das escolas, proporcionais ao desempenho das mesmas no processo avaliativo e que se pautava, principalmente, nas realizações educacionais das unidades de ensino participantes do Programa. A gratificação era concedida de forma progressiva, em cinco diferentes níveis e aumentava ou diminuía de acordo com a aproximação ou afastamento das metas pretendidas

Para cumprir exigência da legislação brasileira, Anthony Garotinho renunciou ao cargo de Governador do Estado do Rio de Janeiro em 2002 a fim de concorrer à Presidência da República, passando então o cargo de Governador do Estado à Benedita da Silva, sua Vice-Governadora e adversária política. Um dos primeiros decretos da nova governadora foi o de não realizar o PrNE no ano de 2002. A realização do Programa foi restabelecida no ano seguinte por Rosinha Garotinho, eleita a nova Governadora no mesmo ano. 
pelo PrNE. No primeiro ciclo de avaliação a gratificação foi delimitada com um piso de $\mathrm{R} \$ 100,00$ (cem reais) para o nível "I" e um teto de $\mathrm{R} \$ 500,00$ (quinhentos reais) para o nível "V". Acrescenta-se que esses valores eram pagos aos diretores, professores e secretários e os demais funcionários da escola eram gratificados com $50 \%$ dos citados valores. Esclarece-se que a adesão ao programa era voluntária, sendo decidida pelas comunidades escolares a participação das escolas da rede. No entanto, qualquer escola que não aderisse ao PrNE teria seu pessoal limitado ao recebimento dos valores equivalentes ao nível mínimo.

De acordo com a justificação oficial, entre os principais objetivos da avaliação externa estavam a modernização da gestão da rede estadual por meio da procura de novos rumos que a tornassem mais eficiente na prestação de seus serviços educacionais e mais transparente na gestão de seus recursos administrativos e financeiros. Para o governo do Estado, o PrNE deveria possuir como eixos norteadores a universalização do ensino, a democratização da gestão escolar com uma maior participação das comunidades internas das escolas; a valorização de seus educadores e demais profissionais da educação; o combate ao baixo nível de escolaridade da população e ao analfabetismo; a superação da defasagem idade-série; a redução da evasão e da repetência e a inclusão social. Além disso, seriam contemplados, também, determinados parâmetros dificultadores do progresso escolar como, por exemplo, os de cunho social (gravidez na adolescência, tráfico e uso de drogas, violência social e doméstica, entre outros) (RIO DE JANEIRO, 2000).

Outro objetivo perseguido no PrNE foi o de aumentar, ou melhorar, o controle do Estado sobre sua rede de ensino básico. Gama (2002, p.1) expressa sua visão sobre as finalidades do PrNE: "claramente, procura corresponder às tendências administrativas que utilizam estratégias de monitoramento e avaliação com vistas a melhorar a gestão governamental, aumentar a eficiência e ampliar o controle social".

A avaliação externa promovida pelo PrNE foi projetada para ser realizada por meio de três Subprojetos Integrados, a saber: (i) avaliação da gestão escolar: a ser praticada em todas as unidades da rede estadual, verificando oito dimensões críticas: planejamento, participação, gerenciamento dos recursos humanos, gerenciamento dos recursos financeiros, infraestrutura física, nutrição escolar, integração escola-comunidade e gestão do processo educativo. O processamento dos dados e informações coletados neste subprojeto, depois de serem analisados separadamente, considerando-se cada indicador, recebiam tratamento estatístico, gerando, assim, os indicadores de gestão escolar de cada unidade; (ii) avaliação do 
desempenho escolar: análise das competências e habilidades cognitivas e sociais de uma amostra do alunado de todas as escolas da rede, mediante a realização de provas especialmente projetadas por especialistas em educação e avaliação. As médias das notas dos alunos, por classe de aplicação de prova, geravam os indicadores do desempenho escolar da unidade; e (iii) avaliação dos indicadores de eficiência escolar: apreciação do nível da eficiência da escola, concebida com a realização de levantamento estatístico de dados dos alunos matriculados na unidade escolar que, após processados matematicamente, geravam as taxas de aprovação, reprovação e evasão escolar das escolas e, após tratamento estatístico, passavam também a fazer parte do resultado final das escolas.

No primeiro ciclo de aplicação do PrNE, cada subprojeto constituía um terço dos indicadores que definiam a classificação de cada escola, tendo, cada um deles, o mesmo peso e importância na classificação geral de todas as escolas avaliadas.

Assim, a avaliação externa do PrNE foi pautada nos resultados alcançados por esses três subprojetos avaliativos, nos quais estavam incluídos os critérios previamente estabelecidos para posicionarem as escolas em níveis de desempenho que serviriam como parâmetros norteadores para o aperfeiçoamento dos serviços educacionais prestados à sociedade local.

O presente artigo está voltado ao primeiro dos mencionados subprojetos em seu primeiro ciclo de realização, entre os anos 2000 e 2003, realizado pela Fundação Cesgranrio como órgão avaliador e trata, especificamente, da apresentação de uma reflexão sobre os impactos da avaliação externa da gestão escolar, elaborada a partir da ótica dos profissionais que participaram do processo avaliativo, tanto na condição de avaliados quanto na de avaliadores, passados 10 anos de sua implementação.

A seguir a esta parte introdutória, são abordadas, em complemento, a questão de investigação, os objetivos, a metodologia utilizada na investigação realizada, constante da classificação da pesquisa, como foi realizada a coleta de dados e informações, além de algumas das limitações presentes no processo desta investigação.

Considerou-se também relevante realizar uma breve "viagem" sobre a constituição da estrutura organizacional montada pelo órgão avaliador, sobre a metodologia exposta na documentação técnica da Fundação Cesgranrio e aplicada na avaliação externa da gestão escolar. Complementando o artigo, são apresentados os resultados da análise de conteúdo das entrevistas e da análise estatística dos dados obtidos pelo inquérito por questionário e, finalmente, é feita uma análise conclusiva da 
investigação objeto deste estudo, em que os autores expõem algumas reflexões sobre o assunto estudado.

\section{Objetivos, metodologia utilizada na investigação e coleta de dados e informações}

Com base nas características do processo avaliativo realizado, nas especificidades do contexto e na sua implementação, procurou-se analisar e interpretar criticamente o modo como a citada avaliação foi desenvolvida. A questão de investigação que orientou esta pesquisa foi a seguinte: Quais os efeitos da avaliação externa do eixo gestão escolar do Programa Nova Escola sobre o modo de pensar e praticar o governo das escolas?

De modo mais específico, procuramos alcançar os seguintes objetivos: (i) conhecer e analisar os processos aplicados na avaliação das dimensões críticas consideradas no processo avaliativo do PrNE; (ii) descrever a atuação da avaliação externa realizada nos processos de redefinição do envolvimento/participação das comunidades escolares na elaboração, execução, acompanhamento e avaliação do planejamento das unidades escolares; (iii) identificar os impactos da avaliação externa realizada sobre o modo de se praticar gestão escolar; e (iv) identificar melhorias na prestação do serviço educativo referenciáveis à avaliação externa do eixo gestão escolar.

Para responder à referida questão de investigação, optou-se pela realização de uma abordagem extensiva que possui uma dimensão qualitativa idealizada por meio de análises bibliográficas, incluindo ainda a recolha e análise de documentos diversos, com destaque para os três relatórios gerais que foram elaborados pela Fundação Cesgranrio que expõem de modo detalhado, além dos resultados do processo avaliativo, com suas conclusões e sugestões, as metodologias utilizadas nos citados processos em seus três anos de aplicação. Além disso, foram feitas entrevistas a atores relevantes dos contextos da avaliação em estudo. A outra dimensão, de caráter quantitativo, se materializou na aplicação de inquérito por questionário, objetivando conhecer a visão de uma amostra de professores que exerciam cargos de diretores de escolas à época da realização da avaliação estudada neste trabalho.

A coleta dos dados e informações que serviram de base a este trabalho empírico foi decidida em função dos objetivos da pesquisa e do objeto de estudo acima explicitados. Assim sendo, como referido anteriormente, as entrevistas, a aplicação dos questionários, as análises bibliográfica e documental foram 
instituídas como as técnicas eleitas para a realização da pesquisa. Os dados coletados por meio dos diversos métodos e técnicas referidos foram confrontados entre si, explorando-se as convergências, mas também as divergências, de modo a conferir maior consistência à análise desenvolvida. Este procedimento, conhecido como triangulação dos dados, norteou as análises finais formuladas, pois, conforme defendem Lüdke e André (1986), permite, de certa forma, que seja assegurada uma maior consistência do estudo, proporcionando a sua validação intersubjetiva.

No desenvolvimento da análise do material recolhido, procuramos respeitar o fluir dos dados, reconhecendo, na linha de Mills (1965, p. 240), que a produção do conhecimento científico é, em certo sentido, uma atividade de tipo artesanal:

Evitemos qualquer norma de procedimento rígida. [...] É imperiosa a reabilitação do artesão intelectual despretensioso, e devemos tentar ser, nós mesmos, esse artesão. Que cada homem seja seu próprio metodologista; que cada homem seja seu próprio técnico; que a teoria e o método se tornem novamente parte da prática de um artesanato. Defendemos o primado do intelectual individual; sejamos a mente que enfrenta, por si mesma, os problemas do homem e sociedade.

No inquérito por questionário, foram seguidos pensamentos de autores como Richardson et al. (1999), Lakatos e Marconi (2001) e Gil (2008) sobre aplicação desses instrumentos em pesquisas acadêmicas. $O$ objetivo foi o de se investigar, também, aspectos sobre a visão de profissionais que à época da avaliação exerciam cargos de diretores das escolas avaliadas.

Os questionários foram aplicados para 120 inquiridos que formaram a amostra final produtora dos dados quantitativos deste $\operatorname{artigo}^{2}$. A análise estatística (descritiva e inferencial) dos dados quantitativos foi realizada com recurso ao software SPSS, da IBM.

Relembramos que os dados mobilizados neste artigo foram recolhidos no contexto de um projeto de pesquisa realizado no âmbito de uma Tese de Doutorado, cujo principal objetivo foi investigar aspectos do subprojeto de avaliação externa da

O processo de aplicação do inquérito por questionário aos diretores que exerciam funções na altura em que decorreu a avaliação externa em análise revelou-se um processo bastante complexo. Num universo de 1858 escolas da rede avaliada, foi constituída uma amostra de 450 diretores cobrindo o conjunto do Estado. Contudo, e não obstante alguma persistência e insistência da nossa parte, apenas foi possível recolher 120 inquéritos válidos (um pouco mais de $1 / 4$ da amostra selecionada). 
gestão escolar do PrNE, que foi apresentada à Universidade do Minho, Portugal, para defesa pública, em 2014.

Destaca-se que, durante o processo de realização das entrevistas, foram contemplados três membros da equipe central do subprojeto da avaliação externa da gestão escolar, vindo a seguir uma representante da UNESCO (Organização das Nações Unidas para a Educação, a Ciência e a Cultura) no PrNE e, em sequência, três professores que participaram da avaliação por estarem, à época de sua realização, lotados em escolas da rede avaliada ocupando cargos de diretores(as). Em todos os casos, foram realizadas entrevistas semiestruturadas, em função do entendimento de que esta modalidade de entrevista proporciona ao entrevistado uma margem significativa de liberdade na organização das suas respostas, permitindo obter testemunhos menos condicionados pelo "efeito de pergunta".

Torna-se importante frisar que, em alguns casos, as entrevistas ocorreram de acordo com aquilo que Bourdieu (1999, p. 1395) define como "gens de connaissance", isto é, com as pessoas com as quais o investigador possuía maior familiaridade e de quem era socialmente mais próximo, como, por exemplo, os representantes do órgão avaliador. Esse aspecto, segundo Bourdieu (1999), configura uma relação social possível de produzir certos efeitos nos resultados das entrevistas, como a sua contaminação causada pela proximidade do investigador com o objeto da pesquisa e, consequentemente, com as pessoas entrevistadas.

No entanto, como salienta o mesmo autor, "todos os tipos de distorções estão inscritos na estrutura da relação de entrevista" (BOURDIEU, 1999, p. 1391), sendo imprescindível que se conheça, reconheça e controle essas distorções, pois elas necessitam ser identificadas para serem dominadas pelo investigador, e esse aspecto é alcançado por meio da constituição de uma prática investigatória refletida e metódica.

No processamento dos resultados das entrevistas foi mobilizada a análise de conteúdo inspirada em Bardin (1988), complementada por considerações e posicionamento de outros autores sobre o mesmo assunto. Pois, como afirma a própria Bardin (1988, p. 30): "a análise de conteúdo (seria melhor falar de análises de conteúdos) é um método muito empírico, [...] não existe o 'pronto a vestir' em análise de conteúdo [...] A técnica de análise de conteúdo adequada ao domínio e ao objetivo pretendidos tem que ser reinventada a cada momento". 


\section{Limitações da pesquisa}

Semelhantemente a todos os métodos utilizados na investigação científica, principalmente nas de cunho social, o método de pesquisa empregado neste artigo apresenta suas limitações, como a seguir exposto: (i) o período de tempo passado desde a realização da avaliação foco deste estudo até a produção deste trabalho gerou algumas dificuldades em se reunir profissionais que participaram do processo avaliativo e que estivessem dispostos a responder aos questionários e a participar das entrevistas; (ii) o número de questionários respondidos não foi o desejado, não obstante os esforços desenvolvidos, tornando essa limitação uma das mais relevantes, pois fragilizou a representatividade da amostra pesquisada em relação ao que se planejava inicialmente; (iii) devido ao tempo passado desde a realização da avaliação, não foi possível entrevistar outros importantes atores do processo avaliativo como, por exemplo, os pais de alunos. Por isso, e por outras razões diversas, algumas categorias de atores escolares relevantes também não responderam ao questionário; (iv) a distância ocorrida entre o momento da coleta de dados e o período da ocorrência do processo avaliativo em estudo, tendo a vantagem de permitir "assentar a poeira", também pode ter influenciado negativamente a capacidade de os inquiridos reconstituírem os processos e os acontecimentos em estudo; e (v) não se pode deixar de considerar que a proximidade do investigador em relação ao objeto investigado, não obstante o esforço de distanciamento crítico adotado, possa ter, em determinados momentos, influenciado as leituras produzidas.

\section{Estrutura organizacional da avaliação da gestão escolar: uma análise sucinta}

Para a realização da pesquisa de campo, o subprojeto de avaliação externa da gestão escolar capacitou nos três anos de aplicação do processo avaliativo, aproximadamente, 200 profissionais, todos com graduação superior em diferentes áreas do conhecimento, sendo que, aproximadamente, $30 \%$ deles possuíam formação em áreas do campo educacional. Todos os pesquisadores eram treinados pelo órgão avaliador e denominados visitadores, e sua tarefa principal era a de colher dados e informações das escolas, por meio da aplicação de instrumentos de pesquisas como: preenchimento dos relatórios de visitas, realização de entrevistas e aplicação de questionários. Os visitadores compunham equipes de visitas por Coordenadoria Regional de Educação (atuais Diretorias Regionais de Educação), sendo cada equipe supervisionada por um especialista da Fundação Cesgranrio denominado "supervisor".

Apesar de ter sido inspirada em avaliações realizadas em países que já possuíam algumas experiências na avaliação institucional no campo educacional, a citada avaliação externa da gestão escolar, de acordo com a Fundação Cesgranrio (2001; 
2002; 2004), obedeceu a um modelo especialmente concebido para o Estado do Rio de Janeiro. Sua arquitetura foi projetada por especialistas da própria Fundação, apoiados por profissionais especializados da SEEDUC/RJ (Secretaria de Estado da Educação do Rio de Janeiro), e seu desenvolvimento conduzido pela instituição avaliadora que o orientou pela e para a realidade estadual fluminense no que diz respeito à educação básica pública local.

Entre os modelos de avaliação que foram estudados pelos especialistas do subprojeto de avaliação externa da gestão escolar, destacam-se os aplicados no Chile (Programa para Aferição da Qualidade da Educação Básica no Chile - SIMCE) e na Colômbia (Escuela Nueva) que, na visão de Wolff(1998), obtiveram relativo sucesso em seus países. Foram estudadas também avaliações realizadas no México e Costa Rica, além de outros de países que apresentavam uma maior e mais antiga experiência no campo da avaliação institucional da educação como Estados Unidos, Inglaterra e França. Não foi, assim, descartada a ideia de que os modelos de avaliação desses países também possam ter, de alguma forma, influenciado o produto final utilizado na avaliação externa da gestão escolar do Rio de Janeiro.

Segundo a Fundação Cesgranrio (2001; 2002; 2004), o citado subprojeto, foco deste estudo, caracterizou-se pelo incentivo à prática da gestão que permitisse às escolas conduzirem um processo de mudanças, ou melhor, transformações necessárias, para o surgimento, construção ou consolidação de um novo padrão de educação no ensino público e, em consequência, de uma escola pública com maior qualidade.

A Fundação Cesgranrio procurou formar uma entidade social, dentro de sua estrutura administrativa, que fosse especificamente responsável pela condução do subprojeto de avaliação externa da gestão escolar. Para isso, selecionou uma equipe de profissionais pertencentes aos seus quadros de pessoal e outros, contratados como prestadores de serviços, que se enquadrassem dentro dos requisitos exigidos à condução de um processo avaliativo considerado inovador e de grande complexidade. Formou-se, assim, a Equipe Central da Gestão Escolar, grupo que esteve trabalhando nos quatro anos da avaliação, incluindo um ano em que a mesma foi interrompida.

Inicialmente, todos os membros da citada equipe de profissionais eram da área educacional: doutores, mestres e especialistas nesse campo do conhecimento. Posteriormente, no decorrer do processo, a equipe foi ampliada com profissionais de outras áreas como, por exemplo, administradores, analistas de sistemas de processamento de dados, logísticos, entre outros. Ressalta-se ter sido também formada uma equipe de apoio exclusiva para atender às necessidades administrativas e financeiras do subprojeto da gestão escolar. 
Dessa forma, estabeleceu-se dentro da Fundação Cesgranrio, praticamente, uma nova organização que possuía considerável independência técnica, administrativa e financeira, para cuidar de forma exclusiva da avaliação que se iniciava. Assim sendo, a Equipe Central se tornou a organização responsável por conduzir a avaliação externa da gestão escolar, coordenada por um acadêmico do campo educacional possuidor de larga experiência em avaliação institucional da educação. Todos os integrantes das equipes conheciam total ou parcialmente as tarefas executadas pela organização da avaliação, formando dessa forma o que Morgan (2007) definiu como uma organização holográfica, incrementando o surgimento de um ambiente onde a flexibilidade e a criatividade eram privilegiadas, surgindo espaço para que se pudesse responder com presteza a possíveis mudanças, dificuldades ou imprevistos.

Houve a preocupação em se realizar uma coleta sistemática de dados e informações em visitas realizadas em todas as escolas da rede (inicialmente, 1.858), procurando-se continuamente, por meio de contatos diretos com os representantes das comunidades escolares, principalmente diretores e professores, esclarecer aspectos relacionados com as características e aplicação da avaliação. Quando ocorria qualquer pendência, normalmente eram marcadas reuniões de esclarecimento, com participação das escolas, SEEDUC/RJ e Fundação Cesgranrio. Esses aspectos, relacionados ao gerenciamento de problemas, obedeciam ao que defendiam Worthen, Sanders e Fitzpatrick (1997) e Patton (1997), a respeito das avaliações de programas.

Acrescenta-se que a SEEDUC/RJ também mantinha uma equipe exclusiva nos seus quadros de funcionários para cuidar dos aspectos relacionados à avaliação externa da gestão escolar. Essa equipe era formada por profissionais que tinham suas origens nas salas de aulas, ou seja, eram todos professores da rede que se encontravam exercendo funções ou cargos técnicos ou administrativos nos gabinetes da citada secretaria, também formando uma equipe possuidora de elevado padrão de conhecimento dos contextos avaliados.

A avaliação foi idealizada, planejada e concebida de acordo com uma sequência que consistiu em recolher dados nas escolas por meio da aplicação de diferentes instrumentos de pesquisa, processar os dados e informações obtidos e disseminar conclusões e sugestões em relatórios gerais e individuais a cada unidade de ensino e à rede de escolas em geral. O processo executado obedeceu, em cada ano de realização, a diferentes eixos de referência, parâmetros que foram utilizados para nortear o processo avaliativo. Essa metodologia se mostrou eficaz na conquista do conhecimento das realidades existentes no contexto das escolas e visou produzir um "olhar" crítico sobre as unidades de ensino avaliadas em diferentes ângulos de sua vida e ação social. 
No primeiro ano, com utilização do estudo da situação das escolas como eixo de referência, o objetivo foi o de conhecer as unidades escolares da rede dentro das peculiaridades e de sua realidade. No segundo ano, procurou-se conhecer onde a escola intencionava chegar por meio de suas ações sociais, políticas e pedagógicas, quais os processos que seriam utilizados para o atingimento de seus objetivos e, por fim, quais os relacionamentos internos e externos à unidade que seriam privilegiados nesses processos. Finalmente, no terceiro ano, ao se estudar o contexto, a cultura organizacional e os resultados obtidos ou almejados pelas escolas, procurou-se conseguir uma perspectiva geral da unidade avaliada em relação aos aspectos mais relevantes de sua vida, considerando suas perspectivas administrativas, sociais, culturais, políticas e pedagógicas.

O Quadro expressa, de forma resumida, a evolução, ano a ano, do primeiro ciclo de avaliação em relação aos eixos de referência que nortearam o processo avaliativo. É importante observar que, em cada ano, com seus respectivos eixos de referências, eram considerados sempre os mesmos indicadores de dimensão crítica. Esses indicadores compunham uma matriz básica de indicadores, voltada para ser analisada de acordo com cada eixo considerado. Ou seja, os indicadores eram analisados, a cada ano, sob diferentes "olhares".

Os modelos conceituais da avaliação, em suas três etapas de realização, foram construídos dentro de uma lógica baseada na racionalidade, obedecendo a preceitos acadêmicos. Pode-se inferir que esse modelo representa uma fusão de três abordagens de avaliação estudadas por Worthen, Sanders e Fitzpatrick (1997), ou seja: avaliação orientada para tomada de decisões, baseada em opiniões de especialistas e baseada na participação, embora com clara dominância do primeiro.

Considerando a primeira delas, a avaliação trabalhou no sentido de que fossem identificadas e coletadas as informações consideradas relevantes sobre a identificação e descrição das realidades de cada escola, com todas as peculiaridades que pudessem ser observadas pelos pesquisadores. Foram levados em conta o valor e o mérito dos objetivos, planejamento e realizações com seus impactos, entre outros aspectos relacionados aos órgãos avaliados. Todos os parâmetros estudados se enquadraram como base para elaboração dos processos que foram utilizados na avaliação, servindo de guias na técnica avaliativa que culminou com a geração de conclusões e sugestões. Estas foram enviadas às escolas com o objetivo de apoiar seus processos de tomada de decisão e a compreensão e solução dos problemas existentes em cada unidade avaliada. Essa abordagem de avaliação voltada para tomada de decisões foi proposta por Cronbach (1963) 
Quadro. Eixos de referências do primeiro ciclo da avaliação externa da gestão escolar.

\begin{tabular}{lc}
\hline Eixos de referência - Primeiro ciclo de avaliação externa da gestão escolar do PrNE \\
\hline Ano I (2000) \\
\hline Orituação & $\begin{array}{c}\text { Ano II (2001) } \\
\text { da prática da gestão escolar. }\end{array}$ \\
\hline Intencionalidade & $\begin{array}{c}\text { Orientada para a avaliação do direcionamento pretendido na gestão de } \\
\text { cada dimensão e do conjunto de dimensões em cada unidade escolar. }\end{array}$ \\
\hline Processos & $\begin{array}{c}\text { Orientada para a avaliação da situação, condições, aspectos e } \\
\text { problemas dos processos próprios de cada dimensão; e a articulação de } \\
\text { todos os processos necessários ao cumprimento das funções de cada } \\
\text { unidade escolar. }\end{array}$ \\
\hline
\end{tabular}

\begin{tabular}{cc}
\hline Relações & $\begin{array}{c}\text { Orientada para avaliação da situação, condições, aspectos e problemas } \\
\text { dos relacionamentos internos, externos e interinstitucionais necessários } \\
\text { ao cumprimento das funções de cada unidade escolar. }\end{array}$ \\
\hline
\end{tabular}

\begin{tabular}{lc}
\hline Ano III (2003) \\
\hline Contexto & $\begin{array}{c}\text { Orientada para a avaliação da adequação ao ambiente físico, social, } \\
\text { econômico e cultural da localidade e região em que está inserida a } \\
\text { unidade escolar; e orientada para avaliação da sua adequação ao } \\
\text { mundo contemporâneo e à Sociedade do Conhecimento. }\end{array}$ \\
\hline $\begin{array}{l}\text { Cultura } \\
\text { organizacional }\end{array}$ & $\begin{array}{c}\text { Orientada para avaliação dos valores, crenças, compromissos éticos } \\
\text { e comportamentos predominantes na prática da gestão escolar e } \\
\text { necessários ao cumprimento das funçães de cada escola. }\end{array}$ \\
\hline Resultados & $\begin{array}{c}\text { Orientada para a avaliação dos compromissos coletivos quanto ao } \\
\text { aluno e sua aprendizagem, explicitados em mudanças de gestão } \\
\text { necessárias ao cumprimento das funções de cada unidade escolar. }\end{array}$ \\
\hline
\end{tabular}

Fonte: Adaptado da Fundação Cesgranrio (2004).

e desenvolvida por Stufflebeam e colegas na década de 1970 do século passado ${ }^{3}$, e foi utilizada como fio condutor do processo avaliativo.

Outras características que também podem ser encontradas na citada abordagem são: o foco no contexto das escolas, objetivando a determinação dos problemas que necessitavam ser resolvidos para a orientação dos objetivos e prioridades propostos nos planejamentos das unidades; a determinação dos recursos, administrativos, técnicos, financeiros e pedagógicos disponíveis; as formas de se utilizar os recursos eficientemente; a identificação do grau de sucesso na execução das tarefas técnicas, administrativas e pedagógicas das escolas; as dificuldades existentes; e a análise detalhada dos resultados obtidos com a finalidade de se verificar os avanços alcançados no processo da sequência da avaliação.

\footnotetext{
3 O modelo desenvolvido por Stufflebeam et al. (1971) ficou conhecido pela sigla C.I.P.P. (contexto, input, processo e produto) e constitui um dos modelos mais utilizados na avaliação de programas.
} 
Quanto aos aspectos em que se registram congruências entre a abordagem utilizada na avaliação com o processo avaliativo "voltada para especialistas", podem-se citar os julgamentos realizados por profissionais especializados em Educação e Administração. Esses julgamentos foram fundamentados em conhecimentos e experiências profissionais que definiram os novos padrões de gestão que seriam sugeridos para aplicação nos processos de planejamento das escolas. A formulação de juízos de valor sobre os problemas estudados na avaliação foi realizada sempre por equipes de especialistas, onde mais de um especialista trabalhava separadamente um mesmo conjunto de parâmetros que formavam um determinado padrão de gestão, objetivando com isso diminuir a subjetividade, além de elevar a possibilidade de se chegar a melhores resultados.

Nas similaridades encontradas com a abordagem "baseada na participação", o conceito defendido foi o de que todo membro da comunidade escolar, funcionários, pais, alunos, professores e, obviamente, os dirigentes, influem na determinação das necessidades da escola, no tipo de dado coletado e na formação de juízo de valor sobre os problemas existentes. Nesse aspecto, observa-se que todos poderiam intervir nos momentos em que ocorria discordância ou conflito entre avaliados e avaliadores.

Os visitadores da Fundação Cesgranrio foram sempre orientados a utilizar uma linguagem adequada a cada grupo pesquisado, respeitando suas diferenças e padrões culturais. No entanto, cabe observar que em algumas escolas não foi possível a ocorrência de uma participação efetiva de sua comunidade escolar no processo avaliativo devido às situações contextuais como, por exemplo, a indisponibilidade de acesso de alguns atores importantes do contexto escolar como pais ou responsáveis pelos alunos, funcionários administrativos ou, até mesmo, em alguns casos, professores.

Outras características das abordagens utilizadas na condução da avaliação podem ser destacadas como as possibilidades de: considerar pontos de vista distintos na construção de juízos de valor sobre o objeto avaliado; ajustar ou alterar o rumo no desenrolar da pesquisa; utilizar de diferentes instrumentos de pesquisa e de várias técnicas para a coleta de dados; valorizar informações consideradas relevantes para os envolvidos na avaliação; compreender a avaliação em relação aos seus objetivos, métodos de planejamento e condução.

\section{Entrevistas: apresentação e análises}

O primeiro aspecto abordado nas entrevistas aos diretores de escolas e representantes do órgão avaliador foi a transformação ocorrida em função da avaliação. Na perspectiva de autores como Teixeira (1997), Belloni (1999), Bolam 
(1999), Gariba Júnior (2005), Falsarella (2006), entre outros, a avaliação não pode ser olhada sem que nela esteja embutido um processo de transformação, uma proposta de ação que busque a modificação de uma determinada situação. Assim, quando se reconhece não ter havido qualquer transformação, o significado é que a avaliação não atingiu o seu objetivo essencial. Ora, a questão central deste estudo focou-se precisamente nas mudanças ocorridas nas escolas na sequência da avaliação externa desenvolvida no âmbito do Programa Nova Escola ( $1^{\mathrm{a}}$ edição: 2000-2003), com ênfase particular na forma de pensar e praticar a sua gestão.

Da análise das respostas sobressai a percepção de que o processo avaliativo não induziu mudanças significativas nas escolas ${ }^{4}$, embora tenha conferido maior visibilidade aos seus problemas e estimulado maior reflexão, interna e externa, sobre as questões educativas. Este desvelar dos problemas chegou a alimentar a crença de que as coisas podiam estar a mudar, contudo, como nos refere um dos diretores entrevistados: "muitas esperanças desapareceram pelo caminho. Faltou ação dos responsáveis pela gestão, não da escola, mas do próprio Estado".

Condições de trabalho precárias, deficiência na formação de gestores, falta de recursos diversos e reduzido estímulo da administração educativa estadual foram as principais causas invocadas pelos diretores inquiridos para explicar o reduzido poder transformador da avaliação externa das escolas realizada no âmbito do PrNE. Apesar de os novos conceitos de gestão (por exemplo, "gestão ativa") passarem a fazer parte do universo lexical dos gestores, essa apropriação parece ter tido poucos reflexos na sua prática cotidiana. Os testemunhos seguintes de dois dos diretores entrevistados sinalizam uma clara ruptura entre a bondade das intenções e a realidade das situações: (i) "Conheci o termo [gestão ativa] durante a avaliação. Os fundamentos do conceito são ótimos. O único problema é que para colocá-lo em prática são necessários recursos e apoio dos órgãos que administram a educação no nosso Estado"; (ii) "Sim [conheço o termo], trata-se de uma utopia em se tratando da escola estadual do nosso Estado".

Não obstante se identificarem, conceitualmente, com a nova forma de pensar a gestão educacional promovida pelo PrNE, considerando a realidade nua e crua das escolas públicas fluminenses, os diretores entrevistados consideraram que não estavam cumpridas as condições institucionais para "passar da teoria à prática".

Costa e Ventura (2005) afirmam que a avaliação de escola se constituirá em perda de tempo caso o investimento realizado no processo avaliativo não reflita na própria

Dos três diretores entrevistados, dois disseram não ter ocorrido mudanças e um afirmou que "na escola as mudanças foram muito poucas, mas passamos a refletir mais sobre a nossa situação ruim dentro da rede". 
instituição, sendo necessário que se identifiquem constrangimentos, dificuldades e insucessos, transformando-os em consequentes estratégias de mudanças geradoras de desenvolvimento e do bem-estar das pessoas e de sua instituição. Se as mudanças nas práticas de gestão das escolas avaliadas não constituem o ponto forte do PrNE, pelo menos, há que reconhecer que, como referem os diretores entrevistados, alguns dos constrangimentos que dificultam essa mudança ganharam uma nova visibilidade. Além disso, a Secretaria de Educação passou a conceder-lhes outra atenção, ainda que essa renovada atenção possa não ter passado de um mero exercício de representação, como sustenta um dos diretores entrevistados: "Como já disse, os beneficios mais palpáveis aconteceram nas pessoas. Na conscientização delas. Na escola, pelo menos a Secretaria de Educação passou durante todo o periodo da avaliação 'simulando' uma maior atenção às escolas".

Simulada, ou não, a maior atenção às escolas, por parte da Secretaria de Educação, teve pelo menos o mérito de criar condições para que alguns melhoramentos na sua estrutura física pudessem ser concretizados. Além disso, a "conscientização" sobre a real situação das escolas fluminenses foi alargada à opinião pública (ou, pelo menos, à opinião publicada), mercê dos debates, induzidos por este processo avaliativo, que extravasaram claramente os muros da escola.

Apesar de o PrNE não incluir nos seus objetivos declarados a comparação entre as escolas da rede e a organização de rankings de excelência, a verdade é que tais comparações e rankings foram realizados, alimentando reações dualizadas ${ }^{5}$. Essa dualização também se observa na opinião dos diretores entrevistados. Enquanto um dos inquiridos considerou a comparação entre as escolas da rede um "aspecto positivo", os outros dois entrevistados adotaram uma posição mais crítica, e um deles justificou a sua oposição a este processo nos seguintes termos: "Cada escola possui a sua própria realidade. Por isso, as comparações são absurdas. $O$ descontentamento com esse aspecto foi generalizado".

Como abordou Ball (2007 apud Lima, 2012), a formação de rankings é um produto típico dos processos sociais existentes no "Estado competidor" do momento,

\footnotetext{
5 Desde os primórdios da história da avaliação educativa, esta constitui uma questão controversa, geradora de posicionamentos opostos entre alguns dos "clássicos" da avaliação. Assim, como esclarece Escudero Escorza (2003), enquanto Cronbach (1963) sustenta que os estudos avaliativos não devem ser comparativos, Scriven (1967) defende que, mesmo considerando os problemas técnicos que a comparação levanta, há vantagem em que esses estudos possam permitir a comparação entre as unidades avaliadas. Por seu lado, Ralph Tyler, considerado o "pai da avaliação educativa", numa das suas últimas entrevistas, sustentou que a verdadeira avaliação é idiossincrática, devendo respeitar as singularidades dos alunos e das escolas, sustentado, por isso, que, em rigor, a comparação entre escolas não é possível. Para uma síntese das ideias defendidas por Ralph Tyler na referida entrevista, ver Escudero Escorza (2003, p. 16).

6 Note-se que, mesmo no caso em que a comparação foi considerada um aspeto positivo, se defendeu que essa comparação não pode ignorar as especificidades de cada escola.
} 
definido por Lima (2012) como "idade da desconfiança". Essa prática é condenada pela maioria dos especialistas na área da avaliação institucional da educação, tendo Dias Sobrinho (2002) salientado que a filosofia existente no Estado-Avaliador, que valoriza a formação de rankings nas avaliações realizadas em instituições educacionais, permite que as organizações sejam comparadas, admitindo classificações hierárquicas de acordo com critérios objetivos e que visam orientar os clientes do "quase mercado" educacional. Assim, essa prática aumenta a competitividade entre os atores avaliados, visando instrumentar o exercício controlador do Estado e diminuindo a sinergia que deve existir entre as escolas de uma mesma rede.

Quisemos também compreender em que medida a avaliação externa desenvolvida no âmbito do PrNE, focada no subprojeto gestão escolar, alterou o padrão de relacionamento ente as escolas e as suas comunidades circunvizinhantes, com particular destaque para o envolvimento dos pais nos processos de tomada de decisão. Os argumentos invocados para justificar um maior envolvimento dos pais nos assuntos escolares podem estar mais ancorados no pilar técnico (as escolas mais eficazes apresentam um forte engajamento dos pais com a escola), ou invocaram o pilar político (os pais, como principais responsáveis pela educação dos filhos, têm o direito de ter voz nos assuntos escolares). O primeiro argumento invoca a qualidade técnica da escola, o segundo complementa-a com a qualidade democrática. Paro (2008, p. 2) sustenta que o respeito pela condição de sujeito, tanto do educando como do educador, pressupõe uma prática de governo das organizações educativas assente em valores democráticos:

Preocupar-se com a prática administrativa de nossas escolas envolve ter em conta a coerência entre meios e objetivos na realização da atividade educativa. A educação, entendida como emancipação humana, precisa levar em conta a condição de sujeito tanto de educandos quanto de educadores. Daí que ela só pode realizar-se de forma democrática, o que significa que a administração que lhe dá sustentação deve ser necessariamente democrática. Considerar as políticas educacionais em suas relações com a prática da gestão escolar significa, portanto, levar em conta a democratização da gestão de nossas escolas.

Também Lück (2000) sustenta que a participação da comunidade escolar pode ser considerada um dos principais pilares sobre os quais assenta a eficácia da escola, pois seu êxito depende da ação construtiva conjunta de sua comunidade interna, por meio da realização de trabalho associado, mediante a existência de harmonia e união que cria um "todo" orientado por uma vontade coletiva. 
Entre os três diretores inquiridos, é consensual a ideia da relevância do envolvimento da comunidade interna e externa das escolas, nomeadamente dos pais dos alunos. A defesa desse envolvimento convoca, prioritariamente, argumentos referenciáveis ao "pilar político": (i) A participação das comunidades interna e externa é fundamental numa escola democrática; (ii) Mesmo antes da avaliação a escola do estado já vinha passando por um processo de democratização; (iii) A educação precisa da participação, principalmente dos pais ou responsáveis pelas crianças.

Contudo, não obstante reconhecerem a relevância da participação da comunidade educativa, os nossos inquiridos não identificam mudanças substantivas na interface entre a escola e a sua comunidade. No caso da comunidade interna, o pouco envolvimento é justificado invocando o recorrente argumento da falta de motivação; no caso da comunidade externa mobiliza-se, conforme expressou um diretor, o argumento da "imputação ambiental" (Sá, 2004), isto é, a reduzida participação deve-se a razões que excluem a responsabilidade da escola: "A comunidade interna não se sente motivada a participar e a comunidade externa, por diversas razões alheias à escola, também tem uma participação muito pequena".

Outro aspecto transversal ao conjunto das entrevistas realizadas com os diretores de escolas foi a importância da formação continuada dos profissionais da educação local. Em diversos momentos, os inquiridos colocaram o problema da deficiência na formação, nomeadamente dos gestores, para se apropriarem do processo avaliativo como base para a introdução de melhorias na prestação do serviço educativo. Gadotti (1999) fundamenta que a formação continuada do magistério contribui para a melhoria da supervisão e apoio técnico às escolas, para uma melhor alocação de recursos, além de colaborar, também, para o preparo da escola em relação aos impactos de inovações introduzidas. Também em linha com a importância da capacitação dos atores educativos como condição para que um processo avaliativo induza melhorias nas escolas, Costa (2007) sustenta que entre as condições necessárias para que um processo avaliativo induza melhorias está a "assessoria qualificada", seja esta prestada por elementos externos (por exemplo, o "amigo crítico"), seja a assessoria interna por recursos qualificados.

Um ponto consensual identificado nas entrevistas foi a concordância geral em relação à importância dos processos avaliativos como condição prévia para a melhoria da escola. Contudo, no processo avaliativo em apreço, os seus principais atores, os profissionais da educação que trabalham nas escolas, em grande parte, não acreditavam que os resultados da avaliação seriam utilizados para a melhoria, associando-os antes a uma avaliação "ao serviço do relatório" (COSTA; VENTURA, 2005). Ou seja, como afirmou Sá (2009, p. 91), quando a avaliação 
"está ao serviço da produção do Relatório, a concepção de escola subjacente é a de uma burocracia ritualizada, em que a avaliação visa sobretudo verificar a conformidade legal, cumprindo um ritual de fachada". Esta desarticulação entre intenções e ações, entre o que se escreve e o que se pratica, surge com toda a acuidade no depoimento de um dos diretores inquiridos:

Toda avaliação é importante. Porém, tem que ser de acordo com as verdadeiras necessidades da escola. A avaliação do Programa Nova Escola transcorreu com todo o apoio da escola, apesar de não ter sido apoiada por ela. No entanto, seus resultados, se colocados em prática, poderiam gerar uma evolução significativa na educação do estado. No entanto, a prática é uma coisa e a realidade é outra. Muita coisa que foi escrita não aconteceu na prática.

$\mathrm{O}$ aparente pouco comprometimento dos avaliados nos subsequentes processos de melhoria não é dissociável da iniciativa externa do processo de avaliação em análise. Um dos diretores inquiridos, quando solicitado a emitir um juízo global sobre a avaliação realizada, afirmou: "Insatisfatória. Apesar de ter movimentado a educação do estado, a avaliação deveria ter sido conduzida juntamente com as escolas e não como uma imposição do Estado".

Como afirma Stufflebeam (2001), citado por Costa e Ventura (2005, p. 4), "os indivíduos têm mais probabilidades de compreender, valorizar e usar os resultados de uma avaliação se estiverem significativamente envolvidos em todo esse processo". Não surpreende, por isso, que os entrevistados considerem que a avaliação externa não dispensa a autoavaliação e que a maioria dos professores inquiridos considere mesmo que esta seria suficiente, dispensando a avaliação externa.

Os entrevistados acabaram por reconhecer que, apesar de as relações com a instituição avaliadora terem sido cordiais e de cooperação, as ações necessárias à melhoria das escolas da rede avaliada se esgotaram na própria avaliação, o que vem reforçar o que já realçamos antes: a "avaliação para o relatório" parece ter-se sobreposto à "avaliação para melhorar".

Segundo a representante da $\mathrm{UNESCO}^{7}$, a avaliação do PrNE, considerando os três subprojetos, apresentou falhas em função, principalmente, da pouca experiência existente no Brasil em se realizar esse tipo de evento em larga escala, referindo também terem existido algumas "falhas" no diálogo entre a Secretaria de

A Secretaria de Estado de Educação do Rio de Janeiro contou com o assessoramento técnico da UNESCO para acompanhar o desenvolvimento do PrNE. 
Educação e a instituição avaliadora. No entanto, afirmou que a avaliação externa da gestão escolar auxiliou a Secretaria de Educação a conhecer e entender seus problemas, pois os indicadores avaliados no processo apontaram várias falhas até então desconhecidas pelos gestores do sistema educacional avaliado. Contudo, na perspectiva da representante da UNESCO:

[...] o que mais atrapalhou o programa foi atrelar uma gratificação ao desempenho sem que os critérios fossem muito bem acordados entre todos os pares, em especial um diálogo mais próximo entre o Sindicato dos Professores e a Secretaria de Educação. O fato de os atores da avaliação não aceitarem integralmente seus critérios contribuiu para que o Programa não fosse bem-sucedido.

A corroborar esta leitura da representante da UNESCO estão igualmente os testemunhos unânimes dos diretores entrevistados. Um deles, quando instado a pronunciar-se sobre a referida gratificação, afirmou: "essa ideia foi o 'ponto fraco'de toda a avaliação. A escola quer a melhoria pela melhoria e não por qualquer tipo de gratificação monetária".

Outro foi ainda mais categórico na reprovação do que denominou de "esmolas desagregadoras": "Um absurdo. Temos que melhorar os salários de todos e dar a todos melhores condições de trabalho. A educação não precisa de esmolas desagregadoras. Todos repudiaram essa ideia".

Como afirmou Santos Guerra (2001, p. 106), quando "os professores rejeitam o processo, jogam à defesa, artificializam o comportamento, negam a evidência, então a avaliação será uma perda de tempo". Se os dados que recolhemos não nos autorizam a afirmar que a avaliação desenvolvida no âmbito do PrNE foi "uma perda de tempo", não podemos deixar de concordar que a reduzida negociação prévia à implementação do Programa terá seguramente limitado o alcance das mudanças que o mesmo pretendia induzir.

\section{Inquérito por questionário: apresentação e análises}

Conforme já exposto, esta pesquisa foi conduzida decorrido um período de tempo considerável após a conclusão do $1^{\circ}$ ciclo do processo avaliativo nela investigado. Dessa forma, muitos dos profissionais que ocupavam cargos de diretores de escolas já tinham terminado seus mandatos e haviam voltado ao exercício da docência em salas de aulas ou foram designados para o exercício de outras funções no âmbito da rede pesquisada. Assim, não obstante o questionário 
ser dirigido prioritariamente aos diretores, apenas 13 inquiridos, dos 120 que responderam aos questionários, ocupavam cargos de diretores. Os demais respondentes ocupavam cargos de professores em suas unidades na época da avaliação, cumprindo, contudo, o requisito de terem participado da avaliação do PrNE. Todos os que responderam à pesquisa participaram dos três anos do primeiro ciclo do processo avaliativo do PrNE, o que nos dá alguma garantia de que possuíam boa experiência em relação à avaliação realizada, conhecendo bem, ou relativamente bem, suas características.

Apesar do esforço desenvolvido pela instituição avaliadora no sentido de clarificar o sentido do processo avaliativo antes de sua realização, a maioria dos respondentes $(82,5 \%)$ afirmou que as informações recebidas não foram suficientemente esclarecedoras sobre todo o processo que estava sendo implantado em função do PrNE e cerca de $11 \%$ informou não ter recebido qualquer informação sobre o Programa antes do início da sua implementação. Esse aspecto pode significar também que, apesar dos esforços realizados para divulgação da avaliação na época de sua implementação, os sistemas de comunicação/informação existentes no interior da rede avaliada possuíam carências, não funcionando adequadamente.

Quanto ao envolvimento da comunidade escolar no desenrolar do processo avaliativo, ficou constatado que a maior parte dos respondentes nas unidades avaliadas $(62,5 \%)$ foi formada por diretores e professores das escolas. Em aproximadamente 1/3 dos casos os respondentes indicaram ter sido envolvida toda a comunidade interna. Estes dados sugerem que, na generalidade dos casos, o processo avaliativo foi conduzido de modo relativamente centralizado, com pouco envolvimento dos avaliados, o que indica que não ocorreu no contexto escolar uma negociação ativa, crítica e reflexiva sobre a avaliação que seria realizada na escola. Como sustentam Costa e Ventura (2005), esta exclusão dos avaliados dos processos avaliativos impede que estes alimentem a emergência de genuínos processos de desenvolvimento organizacional nas escolas.

O debate, além de não ter ocorrido antes do início do processo avaliativo, parece também ter sido bastante limitado após a recepção dos relatórios da avaliação. Quase metade dos inquiridos (46,6\%) informou que os "relatórios foram simplesmente arquivados, não tendo havido debate sobre o conteúdo dos mesmos". Nos casos em que ocorreu algum tipo de debate, só muito excepcionalmente houve a participação de toda a comunidade escolar, incluindo os pais. A ideia de uma avaliação "para o relatório" sai ainda reforçada quando se constata que na maioria dos casos em que houve debate (70\%), daí não resultou nenhum plano de melhoria. Nos restantes $30 \%$ foi elaborado um plano de melhoria que, 
de acordo com os inquiridos, permitiu alcançar os objetivos traçados. As razões invocadas para a não elaboração de planos de melhoria, segundo os respondentes, estão relacionadas ao pouco apoio que afirmam ter recebido dos órgãos estatais responsáveis, principalmente pela Secretaria de Educação, além da recorrente falta de motivação da comunidade escolar. Destaca-se nesse aspecto que nenhum inquirido selecionou a opção "Descrença no sucesso do processo avaliativo" para justificar a ausência de planos de melhoria.

Na linha de outros autores, Rebollo Catalán e Colás Bravo (1993) defendem que os processos avaliativos visam, principalmente, a obtenção de informações que sejam úteis e que possam descrever o valor e o mérito dos objetos avaliados. Além disso, a avaliação também pode proporcionar informação relevante para sustentar os processos de tomada de decisão. Contudo, se os avaliados não se reconhecerem na imagem que lhes é devolvida, dificilmente o processo avaliativo conduzirá às transformações almejadas. A exposição pública das escolas, por meio de comparações relativamente descontextualizadas, gerou em boa parte delas um sentimento de injustiça e insatisfação que pode ter comprometido a apropriação criativa do manancial de dados produzidos no ciclo avaliativo em análise. Na verdade, apenas $15,8 \%$ dos professores inquiridos consideraram que a comparação da sua escola com outras escolas, resultante do processo avaliativo, gerou um sentimento de satisfação na comunidade interna. Em contrapartida, 45,8\% dos inquiridos subscreveram a proposição de que o sentimento foi de "insatisfação, pois a escola foi comparada com outra(s) com mais recursos, sendo, portanto, prejudicada no processo" e 18,3\% referiram que a reação foi de indiferença.

O fato de cerca de $2 / 3$ dos respondentes terem considerado ter havido insatisfação ou indiferença em relação à avaliação, constitui um importante indicador de que o processo avaliativo realizado não terá cativado as escolas para as mudanças almejadas. De resto, quando questionados sobre as dimensões críticas em que as suas escolas sofreram processos de melhoria na sequência da avaliação externa da sua gestão, nenhum inquirido reconheceu mudanças no planejamento da escola, na gestão dos recursos humanos e financeiros, na gestão do processo educativo ou na integração da escola com a comunidade externa. Dos que reconheceram terem ocorrido mudanças, $11,6 \%$ identificaram-se na participação da comunidade interna na vida da escola e 39,6\% na infraestrutura física da escola. Para 38,3\% não houve melhoria nos domínios colocados à sua consideração ${ }^{8}$. Conclui-se, portanto, que, para a generalidade dos inquiridos, as mudanças no modo de praticar a gestão escolar sofreram poucas alterações substantivas na sequência da avaliação deste subdomínio no âmbito do PrNE.

\footnotetext{
8 Acrescenta-se que também nenhum inquirido selecionou a opção "outros avanços".
} 
Para os mesmos inquiridos, as razões que dificultaram a implementação das mudanças consideradas necessárias distribuem-se por um leque de fatores encimado pela falta de motivação dos professores, dadas as condições de trabalho existentes (31,7\%), seguida pela falta de apoio da Secretaria de Educação $(25,8 \%)$, encerrando com a pouca motivação da comunidade interna da escola e a falta de qualificação dos gestores, ambas com 18,3\% .

Apesar de os responsáveis da instituição avaliadora entrevistados terem, de um modo geral, uma visão mais lisonjeira das mudanças ocorridas nas escolas na sequência do processo avaliativo em análise, quando solicitados a responder à questão " $\mathrm{O}$ que falta aos profissionais das unidades escolares avaliadas para terem condições reais de elevar o nível da qualidade de suas gestões?", traçaram um diagnóstico que não difere muito do que foi realizado pelos professores inquiridos. Um dos três entrevistados respondeu: "[Falta] Formação Adequada, Envolvimento e Compromisso com o Resultado dos seus Trabalho e Apoio Institucional"; outro acrescentou: "[Falta] Apoio das coordenadorias locais e regionais e da SEEDUC/RJ, com, por exemplo, programas para a formação de gestores e a educação continuada de professores e de outros profissionais, acompanhamento e ajuda nas suas tarefas e avaliação dos projetos da escola". Mais inovador foi o argumento de que: "Também falta uma integração entre as escolas próximas, visando uma troca de experiências entre elas, integração de projetos, complementação de atividades e deslocamento de profissionais entre as escolas para diferentes trabalhos".

Essa análise surge na linha do que defende Michael Fullan, um dos autores que têm dedicado parte do seu esforço investigativo à compreensão dos processos de inovação e mudança nas organizações educativas. Fullan (2003, p. 95), citado por Costa e Ventura (2005, p. 10), observa: "É uma das maiores ironias da vida: as escolas têm por finalidade ensinar e aprender, no entanto, são péssimas no que se refere a aprender umas com as outras. Se um dia descobrirem como isso se faz terão o futuro assegurado". Mas poderão as escolas explorar este potencial de aprendizagem colaborativa num contexto em que as "lutas concorrenciais" e os "terrores da performatividade" marcam a arena educativa?

As constantes alusões à falta de motivação, a precariedade da participação das comunidades escolares na vida das unidades de ensino e o descaso, frequentemente relatado, dos órgãos superiores das escolas no Estado do Rio de Janeiro apontaram para uma organização possuidora de várias "disfunções" administrativas, o que torna extremamente complexo chegar às soluções corretas para que os inúmeros

9 Uma percepção menos positiva do processo avaliativo desenvolvido no âmbito do PrNE, no seu $1^{\circ}$ ciclo de avaliação, não significa que os inquiridos discordem da avaliação em geral. Na verdade, 83,3\% dos inquiridos consideraram que a avaliação é necessária ou fundamental para a melhoria da educação. 
problemas existentes na escola fluminense sejam afrontados com clarividência. Morgan (2007) sustenta que as organizações com esse tipo de perfil levam as pessoas a elas ligadas, e que delas dependem, a serem traídas por seus próprios processos conscientes ou inconscientes de tomar a decisão certa, sendo levadas, muitas vezes, a enlearem-se em teias cognitivas que as impedem de discernir com um mínimo de objetividade, capturando-as no que este autor designa de "prisões psíquicas".

No entanto, continuando a acompanhar os diferentes modos com que Morgan (2007) enxerga as organizações, torna-se importante frisar que a rede fluminense também possui escolas que se apresentam como organizações de qualidade, possuindo perfis holográficos e inventivos, em que a criatividade de seus membros era privilegiada pelas suas gestões, com pessoas motivadas e dispostas a melhorar seus procedimentos de gestão, acatando e processando os resultados da avaliação com essa finalidade. É certo, também, que a grande carga burocrática existente no serviço público educacional do Estado do Rio de Janeiro muitas vezes amarrava ou tolhia as iniciativas dos gestores das escolas, fazendo a maioria delas adquirirem um perfil que pode ser classificado como aquele que Morgan (2007) definiu como "mecanicista". Em menor número, também existiam unidades que possuíam ambientes participativos, inclusive em relação às comunidades externas, tendendo com isso a se transformarem em organizações possuidoras de perfil "organicistas" de acordo com os conceitos disseminados pelo mesmo autor. Observa-se que escolas com esse perfil tendem a interagir com outras entidades localizadas em seu contexto, conseguindo, com isso, benefícios políticos e sociais.

O certo é que, além das peculiaridades em relação aos tipos de escolas e suas ofertas e modalidades de ensino, dimensão, localização, entre outras, as unidades avaliadas no PrNE possuíam inúmeras e imensas diferenças. Um processo avaliativo que reconhece (e conhece) essas diferenças não é compatível com a organização de "ligas das escolas" que, frequentemente, tomam como mérito o que pode não ser mais do que um "patrimônio herdado" e denunciam como demérito o que em muitos casos não é senão a consequência de desvantagens cumulativas. Quando a escola não reconhece verdade ao juízo avaliativo que lhe é devolvido, dificilmente tomará esse juízo avaliativo como ponto de partida para organizar os seus planos de intervenção.

\section{Conclusões e reflexões críticas sobre o fenômeno investigado}

O Programa Nova Escola e sua avaliação externa nasceram sob a égide de ser um programa inovador que objetivava resolver, ou equacionar, os problemas críticos existentes no contexto da educação básica pública do Estado do Rio de Janeiro. 
No entanto, em sua consecução foram incluídos, ou ocorreram, aspectos que contribuíram para que esse objetivo não fosse alcançado plenamente, podendo-se citar os mais relevantes: (i) ao prever uma classificação das escolas em função dos resultados da avaliação, com pontuações que iam de nível "I" ao nível "V", configurava-se, de forma explícita, a formação de rankings em que as unidades avaliadas seriam comparadas umas com as outras, sem grande consideração pela sua "heteronímia, as suas componentes nomotéticas" ${ }^{10}$; (ii) a agregação da classificação das escolas ao pagamento de premiação aos seus profissionais gerou em muitos deles a sensação de que estavam a ser "comprados" ou, como nos foi afirmado por um dos entrevistados, gratificados com "esmolas desagregadoras"; (iii) o "esquecimento" da realização de um processo de autoavaliação pelas escolas que participaram do PrNE. Ao instituir a avaliação externa, foi ignorada a necessidade de se conhecer a visão das escolas a respeito de sua realidade. Esse fato gerou grande insatisfação nas comunidades escolares que se consideraram excluídas do processo avaliativo, com o surgimento da sensação entre seus profissionais de que sua autonomia foi desconsiderada ou diminuída pelo Governo do Estado; e (iv) a agenda do PrNE foi implementada, desde a identificação do problema, até a institucionalização do programa, sem que houvesse uma discussão ampla com as escolas, nomeadamente com os professores e as suas estruturas representativas. Como consequência, a avaliação surgiu como algo imposto, vindo de fora, criando resistências e não implicando os protagonistas nos processos de mudança.

Outro fato marcante no processo avaliativo realizado foi o da constatação da existência no interior da rede de escolas do Estado de um ambiente de pouca motivação por parte de seu pessoal. A situação socioeconômica dos citados profissionais e o tratamento que os mesmos recebiam, por parte do Estado, não ofereciam à classe condições de trabalho consideradas satisfatórias. Os baixos salários e a pouca possibilidade de crescimento profissional em função da não oferta de cursos de atualização e aperfeiçoamento, entre outros problemas, contribuíram para diminuição da motivação e do nível de participação dos citados profissionais em relação à vida de suas escolas.

Quanto ao aspecto de conhecer e analisar os processos aplicados na avaliação das dimensões críticas, consideradas no processo avaliativo, ressalta-se que a descrição da avaliação externa da gestão escolar do PrNE, realizada por meio dos relatórios

${ }^{10}$ Como afirma Santos Guerra (2002, p. 11), "Avaliar escolas com rigor implica conhecer a especial natureza e configuração que elas têm, enquanto instituições enraizadas numa determinada sociedade: a sua heteronomia, as suas componentes nomotéticas, os seus fins ambíguos, a sua débil articulação, a sua problemática tecnologia [...] Por outro lado é imprescindível ter em conta o caráter único, irrepetível, dinâmico, cheio de valores e imprescindível de cada escola". 
finais dos três anos de aplicação do citado processo avaliativo, foi extremamente rica em informações, expressando em detalhe todos os aspectos da avaliação.

A Matriz Básica de Indicadores e os indicadores de dimensão crítica, em número de oito, depois de compostos, foram amplamente divulgados junto das escolas que seriam avaliadas, por meio de palestras ocorridas em todas as coordenadorias regionais de educação do Estado, de forma a abranger todas as escolas da rede. Contudo, como referimos antes, a maioria dos inquiridos consideraram que as informações recebidas não foram suficientemente esclarecedoras sobre todo o processo.

Observa-se que houve a preocupação de que os indicadores eleitos para compor a Matriz Básica de Indicadores expressassem todo o contexto escolar em função de suas principais dimensões relacionadas à gestão das escolas. Durante o decorrer do processo, os indicadores foram sofrendo as necessárias adaptações de forma a se manterem atualizados em relação aos diferentes eixos de referência adotados nos três anos do ciclo avaliativo em análise.

Quanto ao aspecto de conhecer a influência da avaliação externa realizada nos processos de redefinição do envolvimento/participação das comunidades escolares na elaboração, execução, acompanhamento e avaliação do planejamento das escolas, os dados coletados apontam para mudanças pouco significativas na alteração do padrão de governação dominante. Na época, o sistema de gestão praticado nas escolas públicas estaduais de ensino básico do Estado do Rio de Janeiro apresentava uma estrutura hierárquica que colocava o poder das unidades nas mãos dos seus diretores. Contudo, o que se observava, na prática, era a centralização das decisões mais relevantes nos órgãos da administração da educação pública do Estado, sobrando aos diretores de escolas as tarefas administrativas de rotina. A reduzida autonomia das escolas deixava pouco espaço para a afirmação de áreas de decisão coletiva envolvendo a participação efetiva dos diversos segmentos escolares na vida das unidades.

Por outro lado, foi constatado pela avaliação que as comunidades internas das escolas pouco ou nada reivindicavam em relação aos direitos que lhes são conferidos pela legislação brasileira em relação à sua participação na escola. Esse fato ocorreu, principalmente, em função do desconhecimento por parte das comunidades internas de seus direitos legais, o que não possibilitava sua organização de forma coletiva e compartilhada para cobrar o cumprimento da lei por parte dos representantes do poder público. Por sua vez, a escola, por meio dos seus órgãos de gestão, normalmente, não cobrava essa participação aos pais, permanecendo dessa forma na confortável administração centralizada e menos complexa de ser conduzida. 
Os relatórios produzidos pela instituição avaliadora, nos resultados expostos nos três anos de aplicação do processo avaliativo, dão conta desta deficiência participativa, sugerindo uma série de medidas que podiam ser tomadas pela escola e pelo Estado, no sentido de se discutir, equacionar e procurar resolver o problema.

Em relação ao impacto do processo avaliativo externo sobre o modo de se praticar a gestão nas escolas, percebeu-se, tanto nas entrevistas formuladas quanto nas respostas à pesquisa por questionário, assim como também nas conclusões dos relatórios da instituição avaliadora, que o citado processo não atingiu plenamente seus objetivos. Para além dos constrangimentos já identificados, o quadro político imperante no contexto das escolas avaliadas condicionou o impacto da avaliação, gerando descontinuidade decorrente da mudança de governo, com a consequente redefinição de prioridades. Por outro lado, as comunidades escolares, particularmente os diretores, professores e demais funcionários das escolas, não revelaram particular entusiasmo com este processo avaliativo. Conforme já debatido neste trabalho, uma avaliação do campo educacional que ocorra sem que os avaliados aceitem sua institucionalização e os resultados nela obtidos tende a não apresentar os impactos esperados.

No entanto, mesmo que timidamente, observou-se uma mudança no modo de se debater os problemas da escola. Movimentos sociais das entidades representativas dos profissionais da área da educação no Estado do Rio de Janeiro realizaram uma série de manifestações e debates sobre o PrNE. Vários congressos, seminários e fóruns de profissionais da educação foram realizados durante e depois de realizada a avaliação, objetivando discutir sua realização e seus resultados. Ou seja, a avaliação mobilizou as classes de estudiosos e profissionais da educação do Rio de Janeiro, criando uma consciência mais apurada sobre os vários bloqueios que afetavam (e afetam) a rede de escolas públicas no citado estado.

Devemos, contudo, reconhecer que, na visão da maioria dos profissionais respondentes aos instrumentos de recolha de dados utilizados na nossa pesquisa, os efeitos da avaliação não produziram as esperadas melhorias na prestação do serviço educativo referenciável à avaliação externa da gestão escolar. No entanto, a triangulação dos dados provenientes das várias fontes utilizadas (relatórios do órgão avaliador, entrevistas a distintos atores envolvidos no processo avaliativo e os inquéritos por questionário aplicados aos diretores/professores que participaram na avaliação) permitiu identificar algumas áreas em que se registram melhorias: (i) as infraestruturas físicas das escolas passaram a se apresentar mais limpas, organizadas e com maior apuro; (ii) houve a preocupação em se produzir projetos político-pedagógicos mais estruturados e planejamento mais 
consistente progressivamente orientado para o médio/longo prazo; (iii) passou-se a discutir, mais frequentemente, a participação nas escolas; (iv) valorizaram-se as relações da escola com a comunidade, procurando-se captar novos parceiros que pudessem apoiar as unidades de ensino nos seus projetos sociais e pedagógicos; (v) os profissionais da educação passaram a exigir às instâncias superiores das escolas, de modo mais frequente (e com maior eloquência), medidas para a solução da pouca valorização do magistério público, além de providências para a solução dos problemas críticos existentes nas suas unidades; (vi) os problemas sociais graves apresentados por muitos dos alunos, como, por exemplo, a violência familiar e social, a gravidez na adolescência e o tráfico e uso de drogas, passaram a merecer mais atenção nas arenas de debate das escolas; (vii) os diretores escolares passaram a ter uma concepção mais abrangente da própria noção de gestão escolar, estendo-a para além dos aspectos meramente administrativos; e (viii) foi criada, na Secretaria de Educação do Estado, a Subsecretaria da Gestão Escolar para atender as necessidades das escolas.

No contexto brasileiro, a discussão sobre a gestão escolar tem sido centrada em parâmetros como participação e autonomia, mas também, eficiência, eficácia e produtividade, ou seja, a agenda da democratização convive (de forma tensa) com a agenda da modernização (LIMA, 1994). Não está na "natureza" da avaliação institucional servir uma ou outra agenda. De fato, a avaliação institucional, como qualquer outra modalidade de avaliação, tanto pode servir a agenda da democratização e da emancipação como constituir um pilar essencial de uma gestão autoritária ou de uma agenda neoliberal e de subordinação aos ditames do mercado.

A Constituição Federal de 1988, a Constituição Estadual de 1989 e Lei de Diretrizes e Bases da Educação Nacional de 1996 constituem uma base jurídica que, nomeadamente para os contextos educacionais, aponta para a implantação de uma gestão democrática, caracterizada pela escola autônoma em seus aspectos financeiro, administrativo e pedagógico. Dessa forma, seria de esperar que os citados aspectos sobressaíssem na avaliação externa da gestão escolar do PrNE, o que de algum modo se confirma pela inclusão da participação da comunidade interna e externa nas dimensões a avaliar no eixo gestão escolar. Contudo, não se pode ignorar os apelos de feição mais gerencialista refletidos nas pressões para a apresentação de resultados e na organização dos rankings das escolas da rede.

Como sustenta Sá (2009, p. 108), "se a avaliação não constitui o amuleto que vai esconjurar a crise da educação e da escola, também não deve ser perspetivada como a boceta de Pandora a quem todas as doenças podem ser imputadas". Os dados 
que foram convocados ao longo deste trabalho, se não permitem concluir que a avaliação externa das escolas no eixo gestão escolar, realizada no âmbito do Programa Nova Escola, solucionou todos os "males" de que padeciam as escolas da rede sob a jurisdição da Secretaria de Educação do Estado do Rio de Janeiro, teve pelo menos o mérito de lhes conferir maior visibilidade e de desencadear um amplo e animado debate sobre a qualidade deste importante serviço público, seja na esfera mais recatada das escolas, seja na arena mais aberta dos vários fóruns públicos (seminários, colóquios e congressos) que lhes foram dedicados, com ampla repercussão na imprensa local do Rio de Janeiro. 


\title{
School management external assessment of Rio de Janeiro state's the "Programa Nova Escola": a reflective study on its first performance cycle (2000-2003), after 15 years of its implementation
}

\begin{abstract}
This article aims to reflexively analyze the impacts associated to the school management external assessment, known as the Programa Nova Escola, implemented in the public basic education in Rio de Janeiro State. To achieve the research's goal, participating actors (those being assessed and those conducting the assessment) were given a voice in the investigated context, in order to identify possible changes - induced by the first cycle (2000-2003) of the external assessment of the "school management axis" - in thinking and practicing management in the schools being part of the network. The topic is presented through a short description of the assessment process performed; a concise presentation of the organizational structure set up for the implementation of the assessment; the explanation of the methodology used to achieve the research; and a presentation of the main results of the survey.
\end{abstract}

Keywords: Evaluation. School management. Nova Escola.

\section{Evaluación externa de la gestión escolar del "Programa Nova Escola" en Rio de Janeiro: un estudio reflexivo del primer ciclo de realización (2000-2003), pasados 15 años de su implementación}

\section{Resumen}

Este articulo tiene como objetivo analizar reflexivamente los impactos causados por la evaluación externa de la gestión escolar, denominada Programa Nova Escola, implementada en la educación básica pública del Estado de Río de Janeiro. Para el desarrollo de la investigación, se dio voz a los actores que participan en el contexto investigado, tanto a evaluados como a evaluadores, con el fin de identificar los posibles cambios - inducidos por la evaluación externa del eje de gestión escolar en el primer ciclo de conducción (2000-2003) en el pensamiento y la gestión de la práctica en las escuelas que componen la red propuesta. El tema se presenta a través de una breve descripción del proceso de evaluación realizado; una presentación concisa de la estructura organizacional establecida para la aplicación de la evaluación; la explicación de la metodología utilizada para desarrollar la investigación; y una presentación de los principales resultados de la encuesta.

Palabras clave: Evaluación. Gestión escolar. Nova Escola. 


\section{Referências}

BARDIN, L. Análise de conteúdo. Lisboa: Edições 70, 1988.

BELLONI, I. Avaliação institucional: um instrumento de democratização da educação. Linhas Críticas, Brasília, DF, v. 5, n. 9, jul./dez. 1999.

Disponível em: $<$ http://seer.bce.unb.br/index.php/linhascriticas/article/ viewFile/6711/5418>. Acesso em: 17 fev. 2013.

BOLAM, R. Educational administration, leadership and management: towards a research agenda. In: BUSH, T. et al. Educational management: redefining theory, policy and practice. London: Paul Chapman Publishing, 1999. p. 193-205.

BOURDIEU, P. A miséria do mundo. 3. ed. Petrópolis: Vozes, 1999.

BRASIL. Constituição (1988). Constituição da República Federativa do Brasil: art. 227 da Constituição Federal de 88. Brasília, DF: Senado Federal, 1988. Disponível em: <http://www.jusbrasil.com.br/topicos/10644726/ artigo-227-da-constituicao-federal-de-1988>. Acesso em: 20 out. 2013.

. Lei $\mathrm{n}^{\circ}$ 9.394, de 20 de dezembro de 1996. Estabelece as diretrizes e bases da educação nacional. Diário Oficial da República Federativa do Brasil, Brasília, DF, 23 dez. 1996. Disponível em: <http://www.planalto.gov. br/ccivil_03/leis/19394.htm>. Acesso em: 22 set. 2015.

COSTA, J. A. Avaliação, ritualização e melhoria das escolas: à procura da roupa do Rei... .In: MIGUÉNS, M. I. (Ed.). Avaliação das escolas: modelos e processos. Lisboa: Conselho Nacional de Educação, 2007. p. 229-236. (Seminários e colóquios). Disponível em: $<$ http://www.cnedu.pt/pt/publicacoes/seminarios-e-coloquios/ 754-avaliacao-das-escolas-modelos-e-processos >. Acesso: 22 set. 2015.

COSTA, J. A.; VENTURA, A. Avaliação e desenvolvimento organizacional. Infância e Educação: Investigação e Práticas, Porto, n. 7, p. 148-161, nov. 2005.

CRONBACH, L. J. Course improvement through evaluation. [S. 1.]: Teachers College Record, 1963.

DIAS SOBRINHO, J. Universidade e avaliação: entre a ética e o mercado. Florianópolis: Insular, 2002.

ESCUDERO ESCORZA, T. Desde los tests hasta la investigación evaluativa actual: un siglo, el XX, de inteso desarrollo de la evaluación en educación. Revista 
Electrónica de Investigación y Evaluación Educativa, Valencia, v. 9, n. 1, 2003. Disponível em: <http://www.uv.es/RELIEVE/v9n1/RELIEVEv9n1_1.htm>. Acesso em: 22 set. 2015. DOI: 10.7203/relieve.9.1.4348

FALSARELLA, A. M. As origens da administração escolar. Revista Psicopedagogia On line, maio 2006. Disponível em: $<\mathrm{http}: / /$ www.psicopedagogia. com.br/artigos/artigo.asp?entrID=831>. Acesso em: 16 nov. 2011.

FULLAN, M. Liderar numa cultura de mudança. Porto: ASA, 2003.

FUNDAÇÃO CESGRANRIO. Avaliação externa da gestão escolar 2000. Rio de Janeiro, 2001. Relatório final.

. Avaliação externa da gestão escolar 2001. Rio de Janeiro, 2002. Relatório final.

. Avaliação externa da gestão escolar 2003. Rio de Janeiro, 2004. Relatório final.

GADOTTI, M. Avaliação educacional e projeto político-pedagógico. In: SEMINÁRIO

INTERNACIONAL ITENERANTE DE EDUCADORES, 1.; JORNADA PEDAGÓGICA DA ESCOLA CIDADÃ, 2., 1999, Alegrete, RS. São Paulo: Instituto Paulo Freire, 1999.

Disponível em: $<$ http://www.paulofreire.org/pub/Institu/SubInstitucional12030 23491It003Ps002/Avali_educacional_PPP.pdf]. Acesso em: 19 out. 2011.

GAMA, Z. J. A avaliação do desempenho dos alunos no programa nova escola/RJ - competências, habilidades e exclusão social. Teias, Rio de Janeiro, v. 3, n. 6, jul./dez. 2002. Disponível em: <http://www.periodicos.proped.pro. br/index.php?journal=revistateias\&page $=$ article \&op $=$ viewFile \&path $\% 5 \mathrm{~B} \% 5 \mathrm{D}$ $=116 \&$ path $\% 5 \mathrm{~B} \% 5 \mathrm{D}=117>$. Acesso em: 25 out. 2012 .

GARIBA JÚNIOR, M. Um modelo de avaliação de cursos superiores de tecnologia baseado na ferramenta benchmarking. 2005. $304 \mathrm{f}$. Tese (Doutorado em Engenharia de Produção)-Programa de Pós-Graduação em Engenharia de Produção, Universidade Federal de Santa Catarina, Florianópolis, 2005.

GIL, A. C. Métodos e técnicas de pesquisa social. 6. ed. São Paulo: Atlas, 2008. 
LAKATOS, E. M.; MARCONI, M. A. Fundamentos de metodologia cientifica. 4. ed. São Paulo: Atlas, 2001.

LIMA, L. C. Modernização, racionalização e optimização: perspectivas neo-taylorianas na organização e administração da educação. Cadernos de Ciências Sociais, Porto, n. 14, p. 119-139, 1994.

. Elementos de análise organizacional das políticas e práticas de avaliação escolar. In: WERLE, F. O. C. (Org.). Avaliação em larga escala: questões polêmicas. Brasília, DF: Liber Livro, 2012.

LÜCK, H. Gestão escolar e formação de gestores. Em Aberto, Brasília, DF, v. 17, n. 72, fev./jun. 2000. Disponível em: <www.crmariocovas.sp.gov.br/pdf/ em_aberto_72.pdf $>$. Acesso em: 11 jul. 2011.

LÜDKE, M.; ANDRÉ, M. E. D. A. Pesquisa em educação: abordagens qualitativas. São Paulo: EPU, 1986.

MILLS, C. W. A imaginação sociológica. Rio de Janeiro: Zahar, 1965.

MORGAN, G. Imagens da organização. São Paulo: Atlas, 2007.

PARO, V. H. Política educacional e prática da gestão escolar. In: SIMPÓSIO INTERNACIONAL, 2., Torres; FÓRUM NACIONAL DE EDUCAÇÃO, 5., 2008, Torres. Anais eletrônicos ... Torres, RS: Ulbra, 2008. Disponível em: $<$ http://forum.ulbratorres.com.br/2008/conferencias_texto/PARO.pdf $>$. Acesso: em 15 out. 2011.

PATTON, M. Q. Utilization-focused evaluation. Beverly Hills: Sage Publications, 1997.

REBOLLO CATALÁN, M. A.; COLÁS BRAVO, M. P. Evaluación de programas: una guía práctica. Sevilla: Ed. Kronos, 1993.

RICHARDSON, R. J. et al. Pesquisa social: método e técnica. 3. ed. São Paulo: Atlas, 1999.

RIO DE JANEIRO (Estado). Constituição do Estado do Rio de Janeiro. Rio de Janeiro: Amperj, 1989. Disponível em: <http://www.amperj.org.br/store/ legislacao/constituicao/cerj.pdf>. Acesso em: 30 out. 2013.

. Decreto estadual no 25.959, de 12 de janeiro de 2000. Institui o Programa Estadual de Reestruturação da Educação Pública - Programa Nova 
Escola e dá outras providências. Rio de Janeiro: Assembléia Legislativa do Estado do Rio de Janeiro, 2000. Disponível em: < http://alerjln1.alerj.rj.gov.br/ decest.nsf/a912a1deb5407d36832569d0006f99d9/017a484213a0913603256c3 7006112 ba? OpenDocument>. Acesso em: 23 set. 2015.

SÁ, V. A (auto)avaliação das escolas: "virtudes" e "efeitos colaterais". Ensaio: Avaliação de Políticas Públicas em Educação, Rio de Janeiro, v. 17, n. 62, p. 87-108, jan./mar. 2009. DOI: 10.1590/s0104-40362009000100005

SANTOS GUERRA, M. A. A escola que aprende. Porto: ASA, 2001. . Os desafios da participação: desenvolver a democracia na escola. Porto: Porto Editora, 2002.

SCRIVEN, M. The methodology of evaluation. In: TYLER, R.; GAGNE, R.; SCRIVEN, M. Perspectives of curriculum evaluation. Washington, D.C: American Educational Research Association, 1967.

STUFFLEBEAM, D. L. et al. Educational evaluation and decision-making. Itasca, Ill: F. E. Peacock Publishing, 1971.

TEIXEIRA, A. Educação para a democracia: introdução à administração escolar. Rio de Janeiro: UFRJ, 1997.

WOLFF, L. Educational assessments in Latin America: current progress and future challenges. Washington, D.C.: Inter-American Dialogue, 1998. Disponível em: <http://ww.w.thedialogue.org/PublicationFiles/PREAL\%20 11-English.pdf $>$. Acesso em: 24 set. 2013.

WORTHEN, B. R.; SANDERS, J. R.; FITZPATRICK, J. L. Program evaluation: alternative approaches and practical guidelines. New York: Longman, 1997.

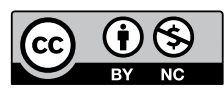

\section{Informações dos autores}

Ovidio Orlando Filho: Doutor em Ciências da Educação, Universidade do Minho. Braga, Portugal. Contato: ovidio@cesgranrio.org.br

Virgínio Isidro Martins Sá: Doutor em Ciências da Educação, Universidade do Minho. Braga, Portugal. Contato: virsa@ie.uminho.pt 